\title{
Safety Training Parks - Cooperative Contribution to Safety and Health Trainings
}

\author{
Arto Reiman, D.Sc. (Tech.), \\ Seppo Väyrynen, D.Sc. (Tech.) and \\ Harri Haapasalo, D.Sc. (Tech.) \\ University of Oulu \\ Oulu, Finland \\ Erja Sormunen, PhD and \\ Tuula Räsänen, $\mathbf{P h D}$ \\ Finnish Institute of Occupational Health \\ Helsinki, Finland
}

\author{
Louise Møller Pedersen, MSc in public \\ administration, $\mathbf{P h D}$ \\ University of Aalborg \\ Aalborg, Denmark
}

\author{
Olli Airaksinen, M.Sc. (Tech.) \\ Sinenkaari Ltd \\ Oulu, Finland
}

\begin{abstract}
Recent debate regarding the possibility for decreasing the risk of accidents within the construction industry has emphasised the need for innovative training methods. Training should combine behaviour- and culture-based approaches, simulate real-life situations, and involve multiple methods. The concept of Safety Training Park (STP) has been developed to meet these challenges. Eighty stakeholders from the Finnish construction industry have been involved in the construction and financing of the STP in northern Finland (STPNF). This unique cooperation has contributed to the immediate success of the park. However, little is known regarding the creation process and how the utilization of the STPNF could be improved. This article presents as a case study the concept, joint creation process and lessons learned this far. Detailed descriptions of the STPNF, findings from focus group interviews, and evidence from the literature are presented with a focus on the pros and cons of the STPNF. The STP is a new and innovative method for safety training that stimulates different learning styles and inspires changes in individuals' behaviour and in the organisations' safety climate. The stakeholders' high commitment, a long-term perspective, and a strong safety climate are identified as preconditions for the STP concept to work.
\end{abstract}

Key Words: Construction education, Learning, Occupational Safety and Health, Safety Training Park, Stakeholder

\section{Introduction}

The construction industry is amongst the most unsafe industries worldwide and accounts for a relatively larger proportion of serious injuries compared to different branches (Ringen et al., 2012). In addition to its high risk for accidents, construction work contains several physical and psychosocial load factors that might affect the ability to work (e.g., Pinto et al., 2011). Accidents and injuries adversely affect human health and well-being. The economic costs of accidents and injuries are considerable, affecting a broad range of stakeholders from employees and their families to employers, coworkers, and society (Feng et al., 2015).

Work in the construction industry is labor-intensive. Despite the general advancements of technology and automation, construction work still includes traditional characteristics of manual work (Zou \& Sunindijo, 2015). Construction work is based on site-specific project-based activities (ibid) and is often performed at shared workplaces, where different stakeholders interact for varying lengths of time (e.g., Aapaoja \& Haapasalo, 2014, McCord et al., 2014). Stakeholders may perform at different levels, often separated by time and space, may have different agendas, and work under severe time pressure and changing working conditions. All of these aspects challenge cooperation and long-term commitment. However, long-term cooperation and commitment are preconditions for implementing successful safety activities. 
A multitude of intervention strategies aimed at reducing occupational accidents and injuries within the construction industry have been proposed and tested, with varying degrees of success (see e.g., Lehtola et al. 2008). Employees' safety behavior and the safety climate of the team and at the organizational level have been identified as essential factors contributing to occupational safety and health (OSH) performance (see e.g., Andersen et al., 2015; Hale et al., 2010; Zohar, 2010). Safety climate is defined: "The shared conceptions of the companies' relative priority of safety compared to other competing priorities, like for instance production" (Zohar, 2010). Thus safety climate relates to the procedures, practices, and kinds of behaviors that get rewarded and supported with regard to a specific strategic focus (e.g., Zohar, 2010). It has been documented how safety climate is a robust leading indicator or predictor of safety outcomes across industries and countries, including the construction sector (Zohar 2010; Kines et al. 2010). A positive safety climate increases the frequency of safety behaviour among employees whereas negative safety climate affects adversely (Zohar, 2014).

Middle managers' and foremen's influence in shaping the safety climate have been emphasized (e.g., Zohar, 2010). Nonetheless, as Kines et al. (2010) highlight, production is usually prioritized over OSH in daily on-site practices. Furthermore, there are often differences between the formal safety policy and the daily OSH practices and informal procedures at the site (Pedersen, 2014). These might influence the possibility of positively affecting OSH; hence, there are no quick fixes. Improving OSH performance require new types of safety training, combining behavior-based and safety climate approaches (DeJoy, 2005). For the OSH literature to move forward, it is important to learn from the pros and cons of these approaches.

A novel approach to OSH training has been created by a variety of stakeholders in the Finnish construction industry. The first safety training park (STP) of its kind in Europe (Confederation of Finnish Construction Industries RT, 2013), namely the Rudus Safety Training Park (RSTP), was constructed in 2009 by a multinational construction company in the city of Espoo in southern Finland. This was followed by a safety training park in northern Finland (STPNF) in 2014, jointly designed and created by 80 stakeholder organizations in the city of Oulu (Reiman et al., 2015). A third STP is currently being constructed in joint cooperation with stakeholder organizations in eastern Finland. STPs are also planned in Sweden and Denmark (see Sikkerhedspark, 2017). In addition to the STP concept described in this study, a few documented examples exist on other company specific learning environments (e.g. Fahmy, 2014; Pawar \& Duggal, 2016).

RSTP and STPNF contain various similarities concerning the target groups, training points and training methods. The most notable difference between the STPNF and other STPs being constructed and the original RSTP is that the former have been jointly created from the beginning by various stakeholder organizations. The multi-stakeholder cooperation in the STPNF creation process is in the specific interest in this descriptive case study. A description and a detailed analysis of the pros and cons of the jointly created STPNF can serve as learning points for similar projects. This is met by answering the research questions;

RQ1: What is the STPNF and what kinds of learning methods are applied there?

RQ2: Which contextual factors have enabled a multiple-stakeholder process between stakeholders with conflicting interests and priorities and what can other learn from this process?

\section{Theoretical Foundations of OSH Training}


Training is an essential element of OSH management. Training activities are designed to improve trainees' skills and knowledge to bring about behavioral changes. While the rationale behind and the level of OSH training may vary among different audiences, it is most commonly related to improving awareness of OSH hazards, expanding knowledge of the causes of illness, injuries and accidents, and to promoting the implementation of effective preventive measures (e.g., Arnold et al., 2005).Various OSH training methods are available, from traditional methods such as lectures and courses, audiovisual materials, OSH card trainings and certificates, and hands-on practices to modern approaches such as virtual reality simulation (Demirkesen \& Arditi, 2015; Zhao \& Lucas, 2015), computer-aided learning, e-learning, remote learning, and online learning (Ho \& Dzeng, 2010).

More engaging training methods that require trainees' active participation seem to provide more efficient results in general (Burke et al., 2011). Moreover, DeJoy (2005) points out that training that combines individual behavior changes combined with culture changes on the organizational level has the best potential for long-term culture change. Glendon et al. (2006) claim that OSH training is a great deal more efficient when utilizing pictures and demonstrations rather than mere lectures or reading relevant material. Brahm \& Singer (2013) propose a combination of first providing larger amounts of information by using less-engaging methods followed by introducing more in-depth knowledge through more-engaging methods.

Learning is an important dimension of training (Demirkesen \& Arditi, 2015). In addition, the transfer of learning must be considered. Even though trainees may acquire new knowledge and skills through training, they still might not apply or use these when they return to work (Arnold et al., 2005). The safety climate at both the organizational level and at the team level contributes to the transfer of learning to the work sites (Zohar, 2010). The safety climate is in practice closely related to organizational factors such as the actual support and opportunities to utilize new skills and knowledge at the actual work environment where the trainee is working (Arnold et al., 2005).

As summarized by Pashler et al. (2008), different individuals may benefit from different learning styles. Nonetheless, practical issues such as the financial costs of the trainings may affect the ability to tailor trainings to fit all individual needs. Barbe et al. (1978) divided learning styles into three categories based on physiological factors: visual (seeing), aural/auditory (hearing), and kinesthetic (touching). A fourth dimension of read/write was later proposed; this learning model is known by the acronym VARK (e.g., Leite et al., 2010).

Trainee characteristics and training design have also been identified as aspects affecting the transfer of learning. In the construction industry, employees tend to be less-educated (Wilkins 2011) and male-dominated (Zou \& Sunindijo, 2015). Furthermore, language barriers for employees from different countries and cultures might exist (Demirkesen \& Arditi, 2015; Loosemore \& Lee, 2002). The selection of training methods should take such factors into consideration (Wilkins, 2011).

\section{Methods and Materials}

This article is based on the OSH literature, a STPNF creation process document analysis (drawings, training point descriptions, administrative documents, and web pages (STPNF, 2017)), and focus group interviews. Four trainee groups representing different-sized companies from the construction industry sector were randomly selected, and volunteered to participate in in-depth focus group interviews (Cooper \& Baber, 2005). In addition, the key individual stakeholders (KIS's) coordinating the STPNF creation phase were interviewed (Table 1). Due to the nature of the 
complex STP phenomenon being studied, the methods used and the focus on contextual factors this study can be described as a case study (Yin, 1984).

\section{“TABLE 1 HERE”}

The interviews involved personnel from different stakeholder levels (Table 1). The interviews for focus groups 1-4 were conducted within one to one and a half months after they had attended the trainings, from spring 2015 to spring 2016. The KIS's focus group was conducted in summer 2016. All interviews were conducted on the companies' premises or at their construction sites. All focus group interviews were recorded and later transcribed and anonymized for researchers' use.

The transcribed and anonymized material was saved to a directory to which all members of the research group had access. To facilitate a systemic analysis of the transcribed data, a cross-sectional classification was made (Mason, 2002). The code list used in the data analyses (training methods, cooperation process, possible obstacles and barriers and key contributors for instance) was based on the key concepts of the research questions and the theoretical foundations presented above. Two researchers independently analyzed the material. Due to differences between the research organizations' software agreements, both NVivo 11 and Atlas.ti 7 were utilized as data analysis tools. The analysis results were later combined and discussed in a researcher meeting.

\section{Analysis}

This article aims to answer what is a STPNF and what kinds of learning methods are applied there. Further, this article aims to answer what kind of experiences can be learned from the multistakeholder co-operation process. The focus group interviews and document analyses address research question 1 . This is followed by analyses of contextual factors contributing to the cooperation and different stakeholders' perceptions of what can be learned from the design process (RQ2).

\section{STPNF}

\section{Multi-stakeholder cooperation}

STPNF was created in 2014 through cross-party cooperation. The first negotiations were held in a construction employer association's board meeting in 2011, where individual board members disseminated their experiences from a visit to the RSTP. The existing training model at the RSTP was seen as a concept that could positively contribute to a safety climate and behavior even though no analyses had been done of the effectiveness of the trainings. As the distance from northern Finland to RSTP was seen as an obstacle (over $600 \mathrm{~km}$ to Oulu and over $1200 \mathrm{~km}$ to the most northern parts of Finland), the board decided to explore practical issues related to arrangements, expenses and to the critical number of participating stakeholder organizations needed to construct a similar kind of STP in northern Finland. Thus, RSTP has strongly contributed to the creation of the STPNF. Cooperation and agreements with RSTP have enabled STPNF to take cues from the concept and allowed it to use the Finnish brand name of STP.

In addition to a board representative, a recently-retired person who had worked in a top management position in a large construction company agreed to voluntarily contact and interview possible stakeholders to assess their levels of interest and willingness. A project manager was assigned as a thesis worker. These three KIS's coordinated the STPNF creation process. 
Based on rough cost estimations (area, ground work, infrastructure, potential users and finances) by the KIS's, it was estimated that a minimum of 30 paying stakeholder organizations was needed in order to be able to initiate the STPNF creation process. The critical mass of 30 stakeholders was achieved within a few months' time. In addition to the commitment, the board showed towards the concept, the KIS's personal contacts and enthusiasm to participate in the STPNF process and in the negotiations should be noted. This is described by an interviewee comment (KIS: consultant): “...as the employer association had made the decision that such a park should be created, I kind of knew that companies' managers had some kind of a right will. The door was open to decision makers' offices. So I always negotiated directly with managing directors or regional directors that had the mandate to make decisions. That certainly speeded up the process".

Currently, the STPNF consortium includes 80 stakeholder organizations (Table 2) which are all allowed to utilize the STPNF premises at their convenience by following jointly agreed-upon rules on STPNF reservations. In this study, a macroergonomic categorization of system actors (stakeholders that are directly affected by the STPNF), system experts (stakeholders who contribute to the STPNF based on their professional backgrounds), system decision makers (stakeholders who make decisions about the requirements, purchasing and implementation), and system influencers (for instance regulators, authorities and media) applied from Dul et al. (2012) is used to introduce different stakeholders' roles and priorities in the STPNF consortium.

\section{“TABLE 2 HERE"}

As mentioned, construction companies differ regarding their prioritizing of and commitment to OSH - often characterized as differences in the safety climate or safety culture (DeJoy, 2005). Roughly nine out of ten construction companies in Finland can be considered as micro companies, employing less than ten employees. It is often a challenge to such companies to invest in $\mathrm{OSH}-$ especially if the outcome of the investment appears vague for them. Moreover, structural, financial, and practical issues can make long-term commitment difficult. Especially larger employers from the construction industry have been strongly involved as system influencers (Table 2). In addition, other industry and service branches have contributed to the STPNF design and creation process. The consortium model and the low price were seen as important motivation factors for joining the process, as described by an interviewee comment (KIS: Part-time CEO): "Yes, that is a huge demonstration of the common will that can be seen in this. I mean hundreds of people participating. I can't even imagine the expenses if this would have been hired by some party to do".

The KIS's abilities as negotiators and coordinators in creating the consortium should be emphasized. During the contract negotiations, KIS's discussed with the companies their expectations and needs, how they could contribute to the training points, and which kinds of topics they preferred to contribute. The KIS's organized training point topic negotiations in which stakeholders that had expressed similar kinds of needs were joined together and instructed to cooperate within the topic.

\section{Costs and Agreements}

The STPNF is governed by the association of STPNF. The annual budget is currently around $120,000 €$, from which practical sustenance and maintenance expenses are covered. In addition, the budget enables different development processes. The budget is covered with annual membership fees of equal amounts (year 2016, 2,500€). In order to spread OSH knowledge more broadly, organizations that do not belong to the consortium are also allowed to reserve STPNF trainings for a 
nominal charge covering computational running costs. Funding for the construction phase from public financers has been minimal and consisted only of compiling a common training material.

In addition to annual membership fees, compensation agreements were allowed in cases where the stakeholder could provide certain work tasks for the STPNF. According to the compensation agreements, stakeholders could pay their membership fees with work output (e.g., clearing the STPNF area or providing electrical installations). Advantages of compensation agreements are highlighted by an interviewee comment (KIS: Part-time CEO): "With that compensation agreement we enabled some funding arrangements... so that we didn't have to go to a bank for loan negotiations or other funding arrangements. Of course, there was uncertainty from the companies as they didn't exactly know whether this is wise or not. But we did have something like six or seven such arrangements".

The equipment at each training point is owned by the contributing organizations. Estimated costs concerning the membership fees and other expenses were discussed openly at the negotiations. Five-year contracts were made to show mutual long-term commitment. Nonetheless, as pointed out in an interviewee comment (KIS: Project manager) below, it was broadly understood that exact cost details for the companies couldn't be communicated during the negotiations: "But to us, it was some kind of mystery at that stage of how expensive it would be to the companies to create training points that they pledged. We didn't have an exact image whether it would cost 3,000 euro or 30,000 euro for the company to create a training point. That depends strongly on the company's own will [as to] which kind of training point they were willing to create".

Schools, universities, and other educational institutions were exempt from the annual membership fees. That made it easy for them to make the decision of participating. In addition, it affected construction companies' willingness to participate as they noticed that their future employees' OSH skills and knowledge could be improved and affected easily through STPNF trainings. This is emphasized in an interviewee comment (KIS: Consultant): "Companies understood that, if a person studying at the branch is allowed to familiarize himself in safety issues in such a practical way that is a good thing. It eases companies into the future when these new professionals step into the working life. That was one thing that was engaging companies to participate". Companies also noticed that through STPNF they could easily improve their company's images.

\section{Description of the Current STPNF}

STPNF is a 1.6 hectare large training area for promoting OSH through different types of learning, networking and for sharing topical in-depth information. STPNF provides real working life demonstrations, possibilities for active participation, reflective discussion, and small tasks such as identifying good and bad solutions at demonstrated work environments. From fall 2014 to summer 2016, around 10,000 trainees have visited the STPNF. Approximately half of the trainees have been system actors and experts at the construction companies and the rest have been future system actors, i.e., students, in addition to system influencers and decision makers.

In total, 22 training points were in use in the STPNF during 2016 (Figure. 1). In addition, two training points will be created later in 2017. The training point topics and the intended training approaches are shown in Appendix A.

\section{"FIGURE 1 HERE"}


Only qualified trainers are allowed to organise trainings. Thus the trainers' instruction can be considered a certificate to be able to conduct trainings in the STPNF. The trainer instruction sessions are conducted by the project manager. The trainer instruction is based on Finnish laws and commonly agreed-upon principles regarding the instruction methods. The common training material has been taught to over 200 individuals from the STPNF stakeholder consortium. The basic idea is that the organizations select trainers from their own personnel. This is a strategic decision, made by the consortium, based on an idea that in-house trainers are more familiar with the organization's processes. The qualified trainers form a heterogeneous group consisting of individuals from different occupational groups, such as OSH managers, OSH representatives, OSH specialists, foremen at a construction company level, and different system actors at other stakeholder organisations. Requirements for the trainers' existing basic skills, knowledge, and position have not been defined.

The basic training course, based on the training material and real-world demonstrations, is intended to take four hours. Nonetheless trainers are encouraged to tailor the trainings on the basis of the trainee group needs. Based on the interviews related to the training materials and the VARK model (Leite et al., 2010), a description of all the learning methods in each training point is provided in Appendix A.

The training points represent demonstrated work environments for the topic discussed. Training points provide new kinds of OSH learning possibilities through engaging training methods. Visual examples of demonstrated work environments are presented in Figures $2 a$ and $2 b$, where good and bad solutions are provided in order to influence individual behavior by inviting trainees' reflections on OSH issues. As STPNF is designed to fit different trainee groups' needs, different training and learning elements can be adopted. Visual, aural/auditory, and read/write learning methods, or their combinations, are used in a vast majority of the training points. As an example, in Figures $2 \mathrm{a}$ and $2 \mathrm{~b}$, the trainees may adopt visual learning by noticing good solutions (approaching the truck and proper fall-arrest systems and personal protective equipment (PPE)) and bad solutions (car crashed, improper fall-arrest systems and PPEs). In addition, training points include descriptive signs where trainees can learn more by themselves and utilize different hazard identification approaches (e.g., the TR method).

\section{"FIGURE 2a AND 2b HERE"}

Kinesthetic learning and especially hands-on learning methods are utilized only at limited training points. As an example, in the training point 9 (Figure 2b) kinesthetic learning methods include the possibility to learn how to ascend and descend the cab and the possibility to check the visual limitations and views in the rear-view camera of the truck. Different kinesthetic learning approaches have been discussed during the creation and utilization phases. Nonetheless, issues such as liability if an accident occurs during the training pose challenges that limit possibilities. Challenges related to liability are highlighted in an interviewee comment (KIS: Project manager): "It was agreed that we won't let them use, for example, chainsaws and circular saws because liability issues are so difficult in such cases. That is some kind of an agreement that has been made."

\section{Learning experiences at STPNF}

In order to maximise the output of the training, the training points are regularly being developed by the stakeholders. As a part of that process, focus groups 1-4 concentrated on collecting in-depth information on system users' experiences on the trainings. Two themes, 1) training point 
arrangements and training approaches, and 2) STPNF area and location, were emphasized in the interviews as factors contributing to the positive and negative learning experiences.

\section{Training Point Arrangements and Training Approaches}

Interviewees emphasized how demonstrated work environments representing bad solutions concretize possible hazards at work sites. This is emphasized in a quotation from the interview discussion: "... and that was a surprise, how poor the visibility is from the cab of a large bulldozer. That you can actually reverse over a car without even noticing that" (Employee) and "Yes, you might assume that when you are high there (at the cab) you can see everything there..." (Foreman) (see Figure 2b). In addition, practical demonstrations engendered interest and discussion not only on OSH issues, but on good practices and solutions in general that could be trained at the park, as emphasized by an interview comment (Employee): “...the topics at that training point represented work phases related to building an apartment house. There were actually all the phases covered that we are doing in practice" (see Figure 2a).

Different tools, aids, and other devices such as PPEs representing currently used and commonly sold solutions are exhibited and shown at various training points. Trainees are allowed to touch and handle them at some training points. In addition, videos showing demonstrated occupational accidents and hazards are used. By focusing on visual and kinesthetic learning, the trainings align with the need of having tangible and understandable training to a diverse population of construction workers. Some interviewees, mainly on the employee side, were critical that the demonstrated work environments showed only the best available equipment that in practice is not always available at work sites. That might challenge trainees' abilities to direct learning transfer to actual work environments and induce frustration, as emphasized in interview comments by two employees: "...fine equipment was shown that you can't see here at work sites. They won't work in practice" and "Then there were those iron hooks for fall arrest body supports that I have never seen at any work site". New knowledge on different kinds of tools that are not available in practice at work sites might create adverse feelings towards OSH and the safety climate at an individual level.

\section{Circumstantial Factors at the STPNF}

STPNF has a permanent location in northern Finland. The permanent location is a consideration that constrains companies' training arrangements in practice. Three of the four focus groups represented work communities that were not working in areas neighboring the STPNF. As a result, timetable and transportation arrangements have been necessary: "That it takes a full day to visit the park if you are coming from this distance" (Foreman) and "Let's say that it's something like 200 kilometers. At that range, each one should be able to visit there" (Employee).

A majority of the training points provide possibilities for both indoor and outdoor activities. In addition, routes between the training points are uncovered. Thus weather conditions are factors that might have an influence on the training experiences and learning, as pointed out by two foremen in the interviews: "One thing was that we were never told that it is an outdoor area and we all were wearing quite sheer clothes. And it was a very cold day and we all were freezing at the end of the training." and "I must say that I couldn't take in all the things that I would have in a good, sunny weather".

\section{Discussion}


Construction work is performed in a changing work environment in which employees cannot be continuously supervised. Thus in many cases, employers must place their trust in their employees' ability to perform work safely in all circumstances. OSH training is one practice to improve employees' skills and knowledge. STPs are platforms for influence at the micro level beyond the rather general OSH laws as they urge trainees, not depending on their positions in the organisation, to share their knowledge and experiences during discussions at the training points. As safety values can be strong and embedded in the group, it is important to be direct and appeal to the trainees' personal values. The focus of each of the training point is to visualise and discuss how practical choices, i.e., selecting good or bad ways to work, that the individual makes during the workday may influence the individual self and their family and co-workers - a very personal approach that would probably appeal to everyone.

STP provides typical system actors, such as employees, the ability to learn how macro-level OSH issues are managed. Furthermore, on a micro level, the presentation of good and bad solutions at the training points enables trainees to identify OSH-related needs at work sites. At the same time, training points provide management and other key decision makers and influencers the ability to identify during a brief, yet holistic visit, work site-level issues that they could incorporate into their management practices.

There are certain common features related to the work force in the construction industry as they tend to be less-educated and male-dominated. Such features can be associated to characteristics like masculinity and risk taking and thus affecting to safety behaviour (see Jensen et al. 2014). In addition current trends on increasing immigration within European Union (EU) countries and from other parts of the world to the EU brings a flow of new workers who are prone to different health risks at their workplace, e.g. due to language barriers, different cultural attitudes to risks and lacking OSH knowledge. Visual and kinesthetic learning methods would ease the training of basic OSH issues, as emphasised by Cameron et al. (2011). A major basis for the STP is to enable efficient learning through a combination of learning methods. At the STP the trainer can tailor trainings from traditional classroom lectures to kinesthetic approaches and combinations to fit the target audience and their characteristics. However, it should be noted, as Verbeek et al. (2011) have emphasized in their review of the effectiveness of manual lifting trainings, that mere OSH training in the STP might not be sufficient if the transfer of learning in practice is disregarded. It is up to companies, as decision makers, to determine how actively they are testing and putting new OSH solutions and practices into use, and providing support and opportunities to utilise learned skills and knowledge at their work sites to facilitate efficient learning transfer.

\section{STP as an Organizational-Level Influencer}

The companies involved in this study consider OSH a strategic value that provides them financial benefits if occupational accidents could be avoided. Unofficial sources indicate that the direct costs of an occupational accident are on average around 7,000-8,000 euro in the Finnish construction industry. The trend in for example accident frequency (the number of accidents per million working hours) rates seems promising, as all the companies included in this study have managed to improve their accident figures during last few years. However, it is debatable how largely this positive trend is depending on the STP trainings compared with other OSH routine and non-routine development actions. As an example in the large national house-building company, the total number of accidents has been reduced from an average of 41.8 ( $S D=8.6$, years 2010-2014) to 15 (year 2015). The company has had all their employees trained at STPs during 2014-2015, thus there is a temporal 
connection between improved OSH performance and STP trainings. Computationally the yearly savings from the year 2015 are 200,000 euro compared with the average level (2010-2014). Similar kinds of computational savings are discussed by Reiman et al. (2017, June) concerning an energy company's (belonging to the STPNF consortium) safety management processes. Thus the reasonable low membership fees are easily covered by reducing the number of accidents. In addition to having financial efforts the membership serves as a mean to improve the company image, affecting thus indirectly to the performance.

STPs are learning environments where different personnel groups meet and discuss together. A constructive dialogue between shop floor and line management, providing motivation for line managers and strengthening the monitoring and learning loops in the OSH system, appear more successful from a longer-term perspective, as Hale et al. (2010) have concluded in their comprehensive evaluation of OSH interventions. This supports the crucial role of foremen and middle managers as in-house trainers in STPs. Foremen and middle managers are the link between the employees, who actually experience and face the risks at work, and the top management who make the decisions related to OSH practices. The middle managers conduct most of the training in the STPNF, thereby ensuring constructive dialogue regarding knowledge transfer from training to the workplace. However, at this stage the STPNF has not systematically incorporated these rolespecific factors in the trainings.

A constructive approach by Hartmann et al. (2010) provides a framework applying role-playing in construction management studies. STP is a forum in which role-playing approaches with individuals acting in different roles could be studied. As a new kind of role Weidman et al. (2016) suggest that a specific group of technology champions as individual, in-house stakeholders could have a significant impact on the implementation of OSH innovations. A key issue in successful implementation is that the technology champions should be able to understand how the innovation would benefit the organisation, and that they receive adequate opportunity to gain practical experience with the innovation. In addition to training, STP is a platform where OSH innovations can be presented and a training facility where technology champions' skills and knowledge can be improved.

\section{STP as a Potential Macro-Level Influencer}

During recent years, the largest construction companies in Finland have succeeded in lowering their accident figures in general; however, accident statistics remain especially high in the smaller companies. This parallels the findings of researchers such as Pinto et al. (2011) that construction companies' size seems to affect OSH performance, as smaller companies tend to have more limited resources for OSH. In addition, differing economic interests, as pointed out by Pedersen (2014), might affect OSH cooperation possibilities.

As the construction sector is economics-oriented, it encourages exploration of channels for cooperation when possible. The STPNF in practice consists of modules owned by the stakeholders. In a sense, the STPNF process can be likened to project alliancing (e.g., Lahdenperä, 2012), in which coalitions of multiple stakeholders with different interests, objectives, and backgrounds act together towards common goals and share the possible risks. A traditional way to manage OSH risks and influence performance is for construction companies to demand compliance with specific OSH issues from their subcontractors through agreements and supervision. However, more positive means can be utilized. Joint efforts to construct the STPNF constitute one positive means to open up new kinds of OSH learning possibilities and provide support to smaller companies. The STPNF creation process was in many ways made possible through large construction companies' resources 
and efforts. Through financial participation, contributing to the STPNF creation process, and providing their personnel the opportunity to be trained at the STPNF, the member organizations' top management have committed their support to OSH at a practical level.

Due to the ownership arrangements through which each of the stakeholders contributes on some level, there is a sense of a collective thinking related to maintaining and developing the STP. Similarly, this contributes to the image that the stakeholders are willing to provide for themselves through the park. As a future challenge, the public sector could support STPs by giving the members advantages in public procurements and/or making OSH engagement a criterion for given offers for public orders. Furthermore, STP trainings could be tailored to contribute to large strategic-level issues in addition to OSH. As emphasized by Leino and Mattila (2000), quality, safety, and ergonomics problems often originate from the same faults. Thus STPs could potentially represent a platform for visualizing and providing learning possibilities on quality faults and effective work processes. Such training issues are under consideration amongst the consortium stakeholders, along with other development issues.

\section{Identified learning aspects and future challenges}

The STPNF construction process itself is proof of macro-level influencing as it shows how rival companies and labour marker organizations can jointly develop new kinds of practices when all stakeholders have a common interest in accident-free construction sites. This view supports the findings by Zwetsloot et al. (2016), who emphasize networking and co-creation as one strategic challenge towards accident-free work in the future. The consortium has proven through the STPNF that they have the potential to act as system influencers and to provide macro-level contributions to strategic OSH learning issues. STPNF organizations have recognized that with reasonable organization-specific investments, they gain the opportunity to benefit from well-organized and sustained training facilities. An important aim of this article is to enable others to learn from the STPNF creation and utilization phases. Based on the analyses above, Table 3 summarizes identified positive learning aspects and challenges that have been faced or could be faced while adopting the STP concept into use. In addition, possible solutions to the challenges are presented in Table 3.

\section{"TABLE 3 ABOUT HERE"}

In order to utilise STP concept most efficiently, stakeholders need to find out which parts of the STP trainings are the best fit for their learning objectives. Some stakeholders, such as schools and vocational institutes, will benefit from the basic training courses that provide a holistic view of the different work phases and related risks at construction sites. A challenge is to measure how the learning objectives are achieved through the STP trainings. Satisfaction could be measured through feedback inquiries. However, as the ultimate aim of the STP trainings is to affect individual skills and behaviour that is a complex phenomenon to be measured. Measuring the change in personal safety behaviour in short and long time frame is identified as a future challenge.

In addition to the variance in trainees' backgrounds, there are identified challenges concerning the certified trainer group. More than 200 trainers have been certified to date to conduct a basic training at the STPNF. The heterogeneity of the trainer group suggests natural differences in how and which kinds of issues are trained in the training points. Trainers are instructed to encourage trainees to share and discuss their own experiences related to the training point topics. The trainer's degree of skill in initiating and feeding the discussions is a key issue. Due to the differences among the trainers' personal abilities and skills, the trainings cannot be evaluated at a large scale using traditional evaluation models and randomised controlled designs. Nonetheless, a realistic evaluation 
approach (e.g., Pedersen et al., 2012) has been designed and is being conducted during the years 2015-2017.

Training points represent realistic work environments. As the literature on OSH training emphasises, more engaging training methods that require trainees' active participation usually provide more positive impacts. A majority of the training points and learning transferred into practice could potentially benefit even more through adoption of some "hands-on" and "learningby-doing" types of instruction. In addition to basic training, more in-depth and hands-on courses focusing on singular training points or on broader STP-wide training topics (such as well-being at work, preventing musculoskeletal disorders by practising good ergonomics, and utilisation and maintenance of PPEs) provide options for experiential learning by deepening trainees' understanding on specific issues. In such cases, the trainer's competence and skills and organization's ability to provide means for transfer of learning in practice are important.

Technological training approaches, such as virtual reality simulations and game-based learning, provide new kinds of learning possibilities for STP trainings in all VARK modalities and combinations. This is in especial interest for students and younger employees who are used to using technical devices. Currently game-based learning has been tested by providing possibilities for validated TR observations through a smartphone application in the STPNF environment. Further, there are plans to provide a smartphone application for testing the level of knowledge before and after the training. Still, the STPNF consortium maintains that physical training environments are needed, since work at construction sites contains and will contain in the future characteristics that require discussion and learning-by-doing approaches. As the STPs are permanently located at specific sites, companies may face practical challenges to facilitate trainings for their personnel who are not located in areas near the STPs. The third STP in eastern Finland will partially alleviate that problem. Nonetheless, an interesting idea for discussion would be whether STPs, or certain parts of them, could be designed for occasional relocation to other localities.

\section{Limitations}

For resource reasons, this study included interviews with representatives of only four companies. Nonetheless, the companies represent different types of actors in the construction industry: two large supplier companies, one medium-sized contractor that also acts as a subcontractor, and a service-providing company. Given these companies have participated in the STPNF creation process, they are likely highly motivated to study whether such projects are profitable. It should be noted that the interviews took place within one to one and a half months after the training session, thus the findings represent only short-term memories and possible impacts. Safety culture change takes a long time and long-term impacts are not discussed in this study. While students at different levels comprise a major portion of the total visitors, they and other relevant stakeholders, such as designers, were not included in this study.

Contextual factors, such as the Finnish insurance systems in which companies' insurance costs are dependent on their OSH performance, influence companies' willingness to improve OSH. The Finnish accident insurance system considers company size in determining insurance premium policies. For smaller companies, the premium rate is based on national statistics at the specific branch and not on the accident risks and level of OSH in the company itself. This policy might affect the smaller companies' motivations to improve OSH in general and through trainings in STPs. The material in this study does not provide accurate means for pre- and post-measurement of company-specific impacts through OSH indicators. 
Interview analyses were conducted separately by two researchers using the same preliminary code lists to facilitate common understanding. Findings were discussed in meetings where generalized topics and analysis codes were agreed.

\section{Conclusions}

New innovative methods for OSH training in the construction industry are needed. STP as a new OSH training concept provides a platform for different kinds of training approaches that facilitate different learning dimensions, and their combinations. The focus of the STP is on affecting individuals' OSH skills, knowledge and eventually behaviour and organisations' safety climate. Furthermore, the STP has the potential to act as a macro-level influencer as it reaches widelyvarying target groups and provides different learning possibilities to fit each target group's needs and expectations for OSH trainings.

STPNF is a multi-stakeholder learning environment that has been created by a consortium of 80 different stakeholders, broadly representing construction industry companies, service providers, unions and associations, and schools and other educational institutions. The wide-ranging consortium, low costs and flexible payment arrangements, active individuals, participatory design and creation process, and the variety of training points representing realistic work environments serve as key success factors for STPNF. However, the permanent location limits stakeholders' opportunities to utilise STPNF. STP concept can be adopted into use in different locations. To help others learn from the STPNF creation process this article includes a detailed description and an analysis of identified learning points, possible upcoming challenges and solution proposals. Future research should be directed to studying the effectiveness of the trainings and further to organizations' OSH performance. Furthermore, the transfer of learning from STP trainings to practical work should be studied.

\section{Acknowledgements}

This study was funded by the Finnish Work Environment Fund (project grant number 114368).

\section{References}

Aapaoja, A. \& Haapasalo, H. (2014). A Framework for Stakeholder Identification and Classification in Construction Projects. Open Journal of Business and Management, 2(1), 43-55.

Andersen, L.P., Karlsen, I.L., Kines, P., Joensson, T. \& Nielsen, K. (2015). Social identity in the construction industry: implications for safety perception and behavior. Construction Management and Economics, 33(8), 640-652.

Arnold, J., Silvester, J., Patterson, F., Robertson, I., Cooper, C. \& Burnes, B. (2005). Work Psychology. Understanding Human Behaviour in the Workplace (4th ed.). Essex: Pearson Education Limited.

Barbe, W.B., Swassing, R.H. \& Milone, M.N. (1979). Teaching through modality strengths: concepts and practices. Columbus, $\mathrm{OH}$ : Zaner-Bloser. 
Brahm, F. \& Singer, M. (2013). Is More Engaging Safety Training Always Better in Reducing Accidents? Evidence of Self-selection from Chilean Panel Data. Journal of Safety Research, 47(Dec), 85-92.

Burke, M.J., Salvador, R., Smith-Crowe, K., Chan-Serafin, S., Smith, A.N. \& Sonesh, CH. (2011). The Dread Factor: How Hazards and Safety Training Influence. Journal of Applied Psychology, 96(1), 46-70.

Cameron, I., Hare, B., Duff, R. \& McNairney, F. (2011). Using pictures in training. The impact of pictorial OSH training on migrant worker behaviour and competence (Res. Rep. 11.2). Scotland: Glasgow Caledonian University, School of Built and Natural Environment.

Confederation of Finnish Construction Industries RT. (2013). Pohjois-Suomeen nouseva turvapuisto on merkittävä satsaus työturvallisuuden parantamiseksi [A Safety Park about to be created in Northern Finland represents a remarkable investment on improving occupational safety]. Retrieved April 4, 2017, from https://www.rakennusteollisuus.fi/Ajankohtaista/Tiedotteet1/2013/Pohjois-Suomeen-nousevaturvapuisto-on-merkittava-satsaus-tyoturvallisuuden-parantamiseksi/.

Cooper, L. \& Baber, C. (2005). Focus groups. In N. Stanton, A. Hedge, K. Brookhuis, E. Salas \& H. Hendrick (Eds.), Handbook of Human Factors and Ergonomics Methods (Chapter 32-1). Boca Raton, FL: CRC Press.

DeJoy, D.M. (2005). Behavior change versus culture change: Divergent approaches to managing workplace safety. Safety Science, 43(2), 105-129.

Demirkesen, S. \& Arditi, D. (2015). Construction safety personnel's perceptions of safety training practices. International Journal of Project Management, 33(5), 1160-1169.

Dul, J., Bruder, R., Buckle, P., Carayon, P., Falzon, P., Marras, et al. (2012). A strategy for human factors/ergonomics: developing the discipline and profession. Ergonomics, 55(4), 377-395.

Fahmy, S. (2014). Hand-on Training for Real World Safety. Living Energy, 10(May), 70-71.

Feng, Y., Zhang, S. \& Wu, P. (2015). Factors influencing workplace accident costs of building projects. Safety Science, 72(Feb), 97-104.

Glendon, A.I., Clarke, S. \& McKenna, E.F. (2006). Human safety and risk management. Boca Raton, FL: CRC Press.

Hale, A.R., Guldenmund, F.W., van Loenhout, P.L.C.H. \& Oh, J.I.H. (2010). Evaluating safety management and culture interventions to improve safety: Effective intervention strategies. Safety Science, 48(8), 1026-1035.

Hartmann, A., Doree, A. \& Martin, L. (2010). A Constructivist Approach for Teaching Research Methodology in Construction Management. International Journal of Construction Education and Research, 6(4), 253-270.

Ho, C-L. \& Dzeng, R-J. (2010). Construction safety training via e-Learning: Learning effectiveness and user satisfaction. Computers \& Education, 55(2), 858-867. 
Häkkinen, K. \& Niemelä, V. (2015). Accident Sources and Prevention in the Construction Industry - Some Recent Developments in Finland. In S. Väyrynen, K., Häkkinen, \& T. Niskanen (Eds.), Integrated Occupational Safety and Health Management - Solutions and Industrial Cases (pp. 1724). Switzerland: Springer International Publishing.

Jensen, S.Q., Kyed, M., Christensen, A-D., Bloksgaard, L., Hansen, C.D. \& Nielsen, K.J. (2014). A gender perspective on work-related accidents. Safety Science, 64(April), 190-198.

Kines, P., Andersen, L.P., Spangenberg, S., Mikkelsen, K.L., Dyreborg, J. \& Zohar, D. (2010). Improving construction site safety through leader-based verbal safety communication. Journal of Safety Research, 41(5), 399-406.

Lahdenperä, P. (2012). Making sense of the multi-party contractual arrangements of project partnering, project alliancing and integrated project delivery. Construction Management and Economics, 30(1), 57-79.

Laitinen, H., Marjamäki, M. \& Päivärinta, K. (1999). The validity of the TR safety observation method on building construction. Accident Analysis and Prevention, 31(5), 463-472.

Lehtola, M.M., Van der Molen, F., Lappalainen, J., Hoonakker, P.L.T., Hsiao, H., Haslam, R.A., et al. (2008). Review and special article: The Effectiveness of Interventions for Preventing Injuries in the Construction Industry: A Systematic Review. American Journal of Preventive Medicine, 35(1), 77-85.

Leino, A. \& Mattila, M.K. (2000). Safety, Ergonomics and Total Quality Management. In W. Karwowski (Ed.), International Encyclopedia of Ergonomics and Human factors (Vol. 1, pp. 13411343). London: Taylor \& Francis.

Leite, W.L., Svinicki, M. \& Shi, Y. (2010). Attempted validation of the scores of the VARK: learning styles inventory with multitrait-multimethod confirmatory factor analysis models. Educational and Psychological Measurement 70(2), 323-339.

Loosemore, M. \& Lee, P. (2002). Communication Problems with Ethnic Minorities in the Construction Industry. International journal of Project Management, 20(7), 517-524.

Mason, J. (2002). Qualitative Researching. London: Sage Publications.

McCord, P.J. \& Gunderson, D.E. (2014). Factors that Most Affect Relationships with General Contractors on Commercial Construction Projects: Pacific Northwest Subcontractor Perspectives. International Journal of Construction Education and Research, 10(2), 126-139.

Osada, T. (1991). The Five Keys to a Total Quality Environment. Tokyo: Asian Productivity Organisation.

Pashler, H., McDaniel, M., Rohrer, D. \& Bjork, R. (2008). Learning Styles: Concepts and Evidence. Aps a journal of the association for psychological science, 9(3), 105-119. 
Pawar, S. \& Duggal, D. (2016). Marketing Strategy for the Industrial Service - Lifecare \& Academy of Tuv Rheinland in the Indian Market Scenario. Imperial Journal of Interdisciplinary Research, 2(6), 228-230.

Pedersen, L.M., Nielsen, K.J. \& Kines, P. (2012). Realistic Evaluation as a New Way to Design and Evaluate Occupational Safety Interventions. Safety Science, 50(1), 48-54.

Pedersen, M. (2014). The tyranny of scarcity: learning and economy at the construction site. Journal of Education and Work, 27(4), 392-408.

Pinto, A., Nunes, I.L. \& Ribeiro, R.A. (2011). Occupational risk assessment in construction industry - Overview and reflection. Safety Science, 49(5), 616-624.

Reiman, A., Airaksinen, O., Väyrynen, S. \& Aaltonen, M. (2015). HSEQ Training Park in Northern Finland - A Novel Innovation and Forum for Cooperation in the Construction Industry. In S. Väyrynen, K., Häkkinen, \& T. Niskanen (Eds.), Integrated Occupational Safety and Health Management - Solutions and Industrial Cases (pp. 145-153). Switzerland: Springer International Publishing.

Reiman, A., Räsänen, T. \& Väyrynen, S. (2017, June). Strategic Safety Management Contributions to Accident Cost Reduction and Financial Benefits in an Energy Company. An abstract and paper to be presented at the Conference of the European Academy of Management, Glasgow, Scotland.

Ringen, K., van Duivenbooden, J.C. \& Melius, J. (2010). Construction safety and health Foreword. American Journal of Industrial Medicine, 53(6), 551.

Sikkerhedspark. (2017). Sikkerhedspark [Safety Training Park Denmark web page]. Retrieved April 4, 2017, from http://www.sikkerhedspark.dk/.

STPNF. (2017). Turvapuisto Pohjois-Suomi [Safety Training Park Northern Finland web page]. Retrieved April 4, 2017, from http://www.pstp.fi.

Verbeek, J.H., Martimo, K.P., Karppinen, J., Kuijer, P.P.F.M., Viikari-Juntura, E. \& Takala, E.P. (2011). Manual material handling advice and assistive devices for preventing and treating back pain in workers. [Cochrane Review]. In Cochrane Database of Systematic Reviews, 2011. Retrieved April 4, 2017, from Ovid Evidence Based Medicine Reviews: Cochrane Database of Systematic Reviews.

Weidman, J.E., Dickerson, D.E. \& Koebel, T. (2016). Technology Champions: A Theory-Based Intervention to Improve Adoption of Occupational Safety Innovations. International Journal of Construction Education and Research, 12(3), 193-207.

Wilkins, J.R. (2011). Construction workers' perceptions of health and safety training programmes. Construction Management and Economics, 29(10), 1017-1026.

Yin, R.K. (1984). Case study research: Design and methods (1st ed.). Beverly Hills, CA: Sage Publications. 
Zhao, D. \& Lucas, J. (2015). Virtual reality simulation for construction safety promotion. International Journal of Injury Control and Safety Promotion, 22(1), 57-67.

Zohar, D. (2010). Thirty years of safety climate research: Reflections and future directions. Accident Analysis \& Prevention, 42(5), 1517-1522.

Zohar, D. (2014). Safety Climater: Conceptualization, Measurement, and Improvement. In B. Schneider \& Barbera K.M. (Eds.), The Oxford Handbook of Organizational Climate and Culture (pp. 317-334). Oxford, UK: Oxford University Press.

Zou, P.X.W. \& Sunindijo, R.Y. (2015). Strategic Safety Management in Construction and Engineering (1st ed.). Chichester, UK: Wiley-Blackwell.

Zwetsloot, G.I.J.M., Kines, P., Wyboc, J-L., Ruotsala, R., Drupsteen, L. \& Bezemer, R.A. (2016). Zero Accident Vision based strategies in organisations: Innovative perspectives. Safety Science, 91(Jan), 260-268. 